\title{
Observations on the Mechanisms of High Resistance Junction Formation in Aluminum Wire Connections
}

\author{
Dale Newbury* and S. Greenwald ${ }^{\dagger}$ \\ National Bureau of Standards, Washington, D.C. 20234
}

June 19, 1980

\begin{abstract}
The basic mechanism of high resistance junction formation in duplex connectors wired with aluminum was investigated. Laboratory experiments to simulate loose connections were made both in actual duplex connectors and in an experimental apparatus. Microstructural observations were made by scanning electron microscopy and $\mathrm{x}$-ray microanalysis of the structures formed at the interfaces between the circuit components during high resistance junction formation. At the iron screw/aluminum wire interface, the arcing process which occurs in a loose connection causes high temperatures in excess of $1500{ }^{\circ} \mathrm{C}$ and material transport between the components. Under these conditions, aluminum and iron react to form intermetallic compounds such as $\mathrm{Fe}_{3} \mathrm{Al}$ and $\mathrm{FeAl}_{3}$. The formation of an extensive zone of these compounds adjacent to the iron-aluminum interface in duplex connectors was revealed by electron metallography. In duplex connectors tested to glow failure, the formation of intermetallic compounds such as $\mathrm{CuAl}_{2}$ and $\mathrm{Cu}_{2} \mathrm{ZnAl}$ was observed at the brass plate/aluminum wire interface. These intermetallic compounds have a resistivity of the order of $100 \times 10^{-6} \mathrm{ohm}-\mathrm{cm}$ or higher which may provide sufficient resistence at the current-carrying interface to lead to significant $I^{2} R$ heating losses at the interface.
\end{abstract}

Key words: Aluminum wiring; duplex connectors; high resistance junctions; junction resistance; scanning electron microscopy; x-ray microanalysis.

\section{Introduction}

Overheating of electrical connections has been observed in various studies of aluminum wiring used in residential branch circuits $[1]^{1}$. The implications of this overheating for damaging the connection, destroying the device, and possibly causing fire have been established. It is not obvious however why the components involved, which typically include aluminum wire, a steel screw with a thin brass, tin or zinc plating, and a brass plate, should produce overheating since all are good conductors. Engineering studies have revealed that the overheating occurs mainly in loose connections [2,3]. The overheating is often accompanied by the emission of visible light, the so-called glow phenomenon, an apparent result of electrical arcing.

Loose screw connections in the receptacle may result from one or more of the following causes:

(a) Expansion and contraction of the connection. Heating caused by the $I^{2} R$ losses in the connection is the principal means of expansion and contraction [2,3]. Receptacles located in outer walls are also subject to heating and cooling without the need for any electric current in the

\footnotetext{
* Center for Analytical Chemistry, National Measurement Laboratory.

${ }^{+}$Center for Consumer Product Technology, National Engineering Laboratory, Retired, 1980.

${ }^{1}$ Figures in brackets refer to literature references at the end of this paper.
}

branch circuit. Such temperature swings cause an alternate compression and relaxation of the connection mainly because of the difference in expansion rates of aluminum and steel.

(b) Creep. Aluminum is a metal which may exhibit creep or relaxation under stress at ambient temperatures. This effect in the aluminum wire is dependent on its composition and heat treatment during manufacture and on the temperature at which the connection operates. Related to this problem is the very limited mechanical compliance of the screw-wire-brass plate system found in these receptacles $[2,3]$.

(c) Workmanship. A receptacle in which the screws are not sufficiently tightened during installation is a source of potential problems. Even when the screws are satisfactorily tightened outside the wall box during installation, some of the screws may be loosened in the act of pressing the receptacles back in their box. The stiffer the wire, the more likely this will occur $[2,3]$.

In a tight connection very little heat is dissipated at the electrical interface. With $15 \mathrm{~A}$ of current flowing across the junction, the power consumed is on the order of $80 \mathrm{~mW}$. With the same current flow, power dissipation as high as $36 \mathrm{~W}$ has been reported with a glowing connection [1]. One particular glow situation was reported to have been sustained for over $100 \mathrm{~h}$ although the time duration is 
usually shorter [3]. Temperatures as high as $400{ }^{\circ} \mathrm{C}$ have been measured in this study at the break-off tab (fig. 2). In the center of the glow area itself, the visible color may vary from a dull red to a bright white, indicating maximum temperatures in excess of $1200-1300^{\circ} \mathrm{C}[1]$.

The origin of the junction resistance leading to resistive heating in aluminum wire/steel connections is not well understood. Previous work on copper/copper junctions by Suzuki et al. [4] indicated that the formation of filamentous $\mathrm{Cu}_{2} \mathrm{O}$ between the loose copper conductors was responsible for high junction resistance. This observation suggests the possibility that the formation of aluminum oxide and/or iron oxide might be an important mechanism for the development of high resistance junctions in aluminum wire/iron screw connections. In the present study, the microstructures of components from laboratory simulations of aluminum-iron glowing connections as well as actual wall receptacles tested at the onset and after the full development of glow formation were examined by scanning electron microscopy and x-ray microanalysis to determine the underlying mechanism of high resistance junction formation.

\section{Experimental Methods}

Two different types of electrical connections were examined. In order to study the initial stages of the glow phenomenon, it was necessary to simulate a loose connection with electrical contact established in a known location. This was accomplished in an experimental apparatus designed to create a controlled contact region (fig. 1). Actual residential duplex receptacles were tested to simulate service failure (fig. 2).

\subsection{Simulated Wire/Screw Contacts}

To simulate a glow failure in a controlled location on an aluminum wire/iron screw complex a simple apparatus was constructed (fig. 1). In this device, which was essentially a micromanipulator, an aluminum wire was pressed against the head of a brass-coated steel 8-32 screw taken from a commercial receptacle. The gap between the wire and screw was adjustable. Because of the curved geometry of screw and wire (longitudinal axis perpendicular), contact area was minimal.

Voltage was provided by a variable ac source, and a resistor of about $1 \Omega$ in series with tile wire-screw connection was used to control the current level to prevent gross instabilities.

In operation, voltage was first removed from the fixture and the thumbscrew turned until the test wire and steel screw just made contact as indicated by an ohmmeter. Next, voltage was applied and current increased to $15 \mathrm{~A}$. If a

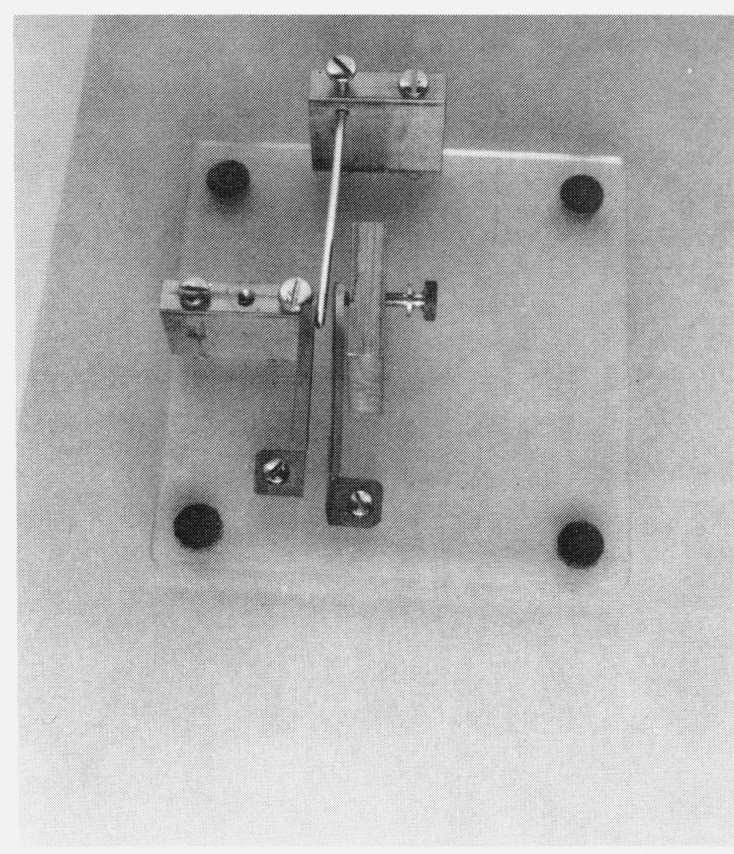

Fisure: 1. Apparatus for controlled wire/screw arc experiments.

glow did not appear within 2 or $3 \mathrm{~min}$, the thumbscrew was backed off very slightly. Arcing (defined as a low voltage, high current sustained discharge) would then be observed visually and a sustained glow could frequently be obtained. In order to avoid the effects of residual contaminants on the test wire and screw, both were cleaned with trichloroethylene and acetone and rinsed with distilled water and methanol.

The specimens produced with this simple apparatus were primarily used for examination of the initial phases of the glow phenomenon, since the location of the electrical contact could be carefully controlled.

\subsection{Residential Connections}

The second set of experiments examined the situation shich resembled the conditions in house wiring. Here the goal was to induce a glow under the head of a screw in an actual residential receptacle. To this end 10 duplex receptacles were mounted on a rack and wired in series with \#12 gage aluminum wire. All receptacles in the experiment were of a common commercial variety using steel screws with a very thin brass or zinc plating. Figure 2 shows a typical device removed from the rack for observation. The connections were tightened to a relatively low torque of about $0.4 \mathrm{nt}-\mathrm{m}$ ( $4 \mathrm{in}-\mathrm{lb})$, in order to try to induce glow in a few current cycles. A current of $40 \mathrm{~A}$ ac was periodically passed through all connections. A complete cycle took 20 min with equal "on" and "off" times. High currents were employed to accelerate the development of glow failures in order to obtain suitable samples in a 


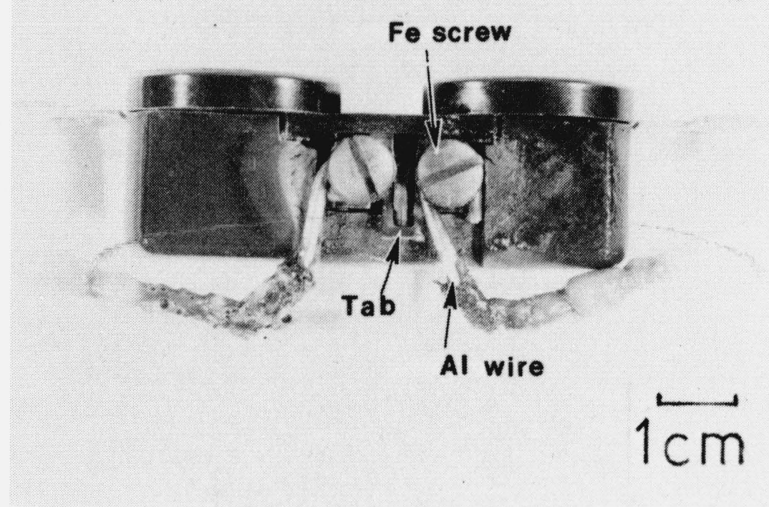

FIGURE: 2. Duplex junction box showing wire and screw components and location of tab for temperature measurements.

reasonable time. Previous work indicated that glow failures could be obtained over a wide range of current, 0.8-50 A [1].

Some of the connections tested developed a glow failure which could be sustained for considerable time. Sample "A" was one such example (see table 1) which developed a glow after only $8 \mathrm{~h}$ of cycling. This specimen was left in the circuit and continued to glow, but was finally removed after 4 more hours had elapsed. The total number of "on".-"off" cycles at that time was 36 . In other tests, e.g., specimens C and D in table 1 , the test was interrupted at earlier stages in the development of the glow phenomenon in an attempt to trace the sequence of the events. Temperatures were measured during the test with a thermocouple connected to an electronic digital thermometer at the position shown in figure 2 .

Samples were prepared for scanning electron microscopy and $x$-ray microanalysis. In the case of the simple wire/screw contact experiments, the region of the contact could be examined directly in the scanning electron

TABI.E 1. Laboratory test conditions of household wiring fixtures

\begin{tabular}{ccccc}
\hline Sample & Cycles* & Current & $\begin{array}{c}\text { Maximum } \\
\text { Temperature** } \\
{ }^{\circ} \mathrm{C}\end{array}$ & $\begin{array}{c}\text { Time } \\
\text { of } \\
\text { sustained } \\
\text { glow }\end{array}$ \\
\hline A & 36 & $40 \mathrm{~A}$ & 350 & $4 \mathrm{~h}$ \\
B & 36 & $40 \mathrm{~A}$ & 360 & $4 \mathrm{~h}$ \\
C & 12 & $40 \mathrm{~A}$ & 340 & $\mathrm{n}-\mathrm{d}$ \\
D & 16 & $40 \mathrm{~A}$ & $\mathbf{2 6 0}$ & $\mathrm{n}-\mathrm{d}$ \\
\hline
\end{tabular}

n-d-visible glow not detected; the test was interrupted to study the incipient failure.

* A cycle consisted of $10 \mathrm{~min}$ "on" followed by $10 \mathrm{~min}$ "off."

** Temperature measured at tab on fixture. microscope without prior preparation. For the household fixtures, metallographic sections were prepared through the wire/screw/brass plate junction. Because of the three dimensional nature of the junction, it was not always possible to simultaneously intercept the region of glow interaction at the wire/screw interface and the wire/brass plate interface. An optical microscope incorporated in the scanning electron microscope allowed direct comparison between the optical and electron metallography of the sample.

X-ray microanalysis was carried out with an energy dispersive $x$-ray spectrometer (EDS) attached to the scanning electron microscope (SEM). The elements of interest in the analyses, aluminum, iron, copper, and zinc, have characteristic $x$-ray energies which are sufficiently separated in energy so that no peak overlap occurs. For the flat metallographic sections, quantitative x-ray microanalysis was possible. The NBS theoretical matrix correction procedure for x-ray microanalysis, FRAME C, was used to reduce the measured $x$-ray spectral intensities to quantitative compositional values [5]. Pure elements were employed as standards, and the beam energy was 20 $\mathrm{keV}$ for all analyses. Under such analytical conditions with well resolved peaks, previous experience in the analysis of known samples indicates that FRAME C analyses lie within 5 percent relative of the correct value in 90 percent of the cases tested when major elements (concentrations greater than $10 \mathrm{wt} \%$ ) are being considered.

Quantitative x-ray microanalysis of the irregular surfaces observed on the aluminum wire and iron screw couples from the loose-contact simulation was performed with the NBS theoretical matrix correction procedure for rough surfaces, FRAME $P$ [6,7]. This is a recently developed procedure for the analysis of samples which deviate from the ideal sample, e.g., flat, polished, and set at a specific angle to the x-ray detector. The typical error limits for FRAME $P$ analysis have not yet been determined, but preliminary testing suggests that an error range of \pm 20 percent relative should be obtained in most cases.

\section{Experimental Results}

\subsection{Wire/Screw Loose Contact Simulation of Glow Failures}

\subsubsection{Free surface}

The regions on the surfaces of the aluminum wire and iron screw associated with a glow failure were examined by scanning electron microscopy. Examples of the structures observed on the wire and screw are shown in figures 3(a) (wire surface) and 4(a) (screw surface). Craters are observed on both surfaces. These crater surfaces have a 


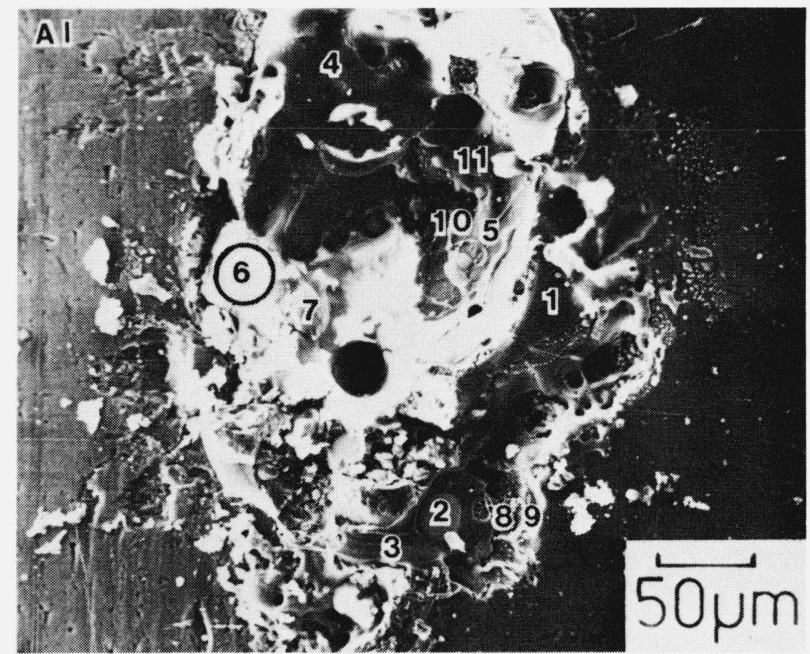

FIGURE 3(a). Damage crater observed on aluminum wire after loose junction glow simulation.

Analyses at points indicated are listed in table 2 (SEM image).

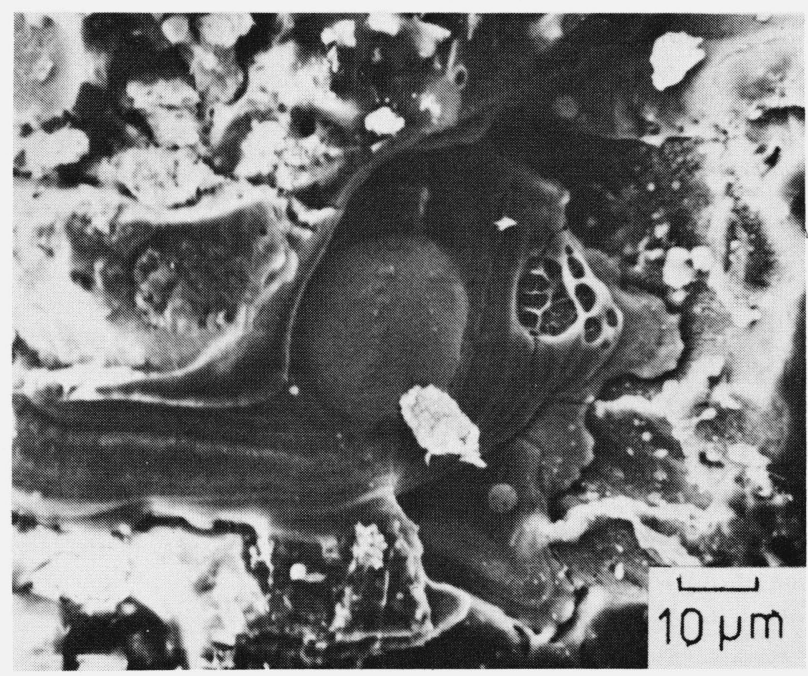

FigurE 3(b). Structure located at position 2 in figure 3(a) (SEM image).

smooth appearance which appears to be a result of melting and solidification. X-ray microanalyses of the areas indicated in figures 3(a) and 4(a) are listed in table 2. The analyses reveal that both aluminum and iron are present in significant amounts within both crater regions. Since the surrounding matrix material is either nearly pure aluminum or nearly pure iron, the intimate mixing of these elements in the crater regions indicates that significant material transport occurred between the wire and the screw during the glow phenomenon.

Close examination of the craters revealed a number of interesting features. Ball-like structures, marked in figures $3(\mathrm{~b})$ and 4(b), found in both craters contain mostly iron,

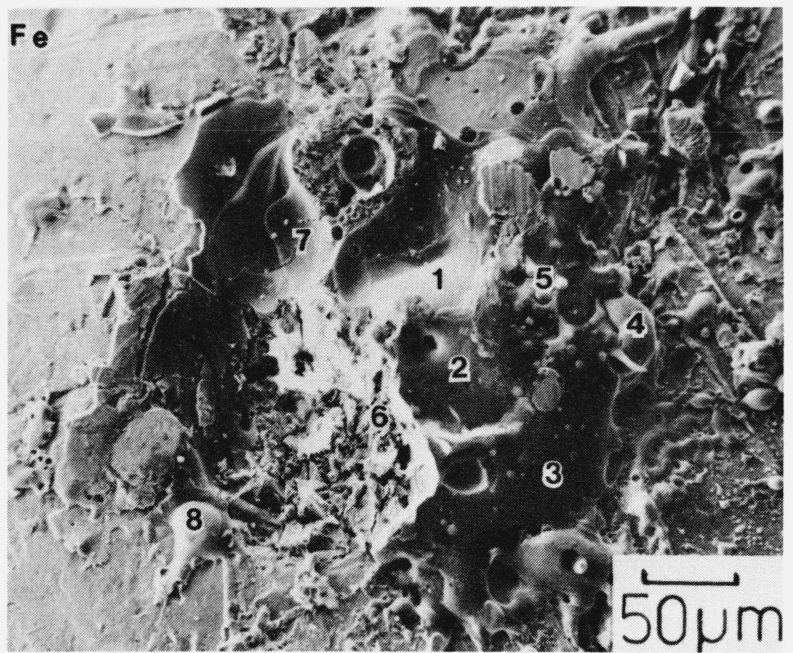

Figure 4(a). Damage crater observed on iron screw after loose junction glow simulation.

Analyses at points indicated are listed in table 2 (SEM image).

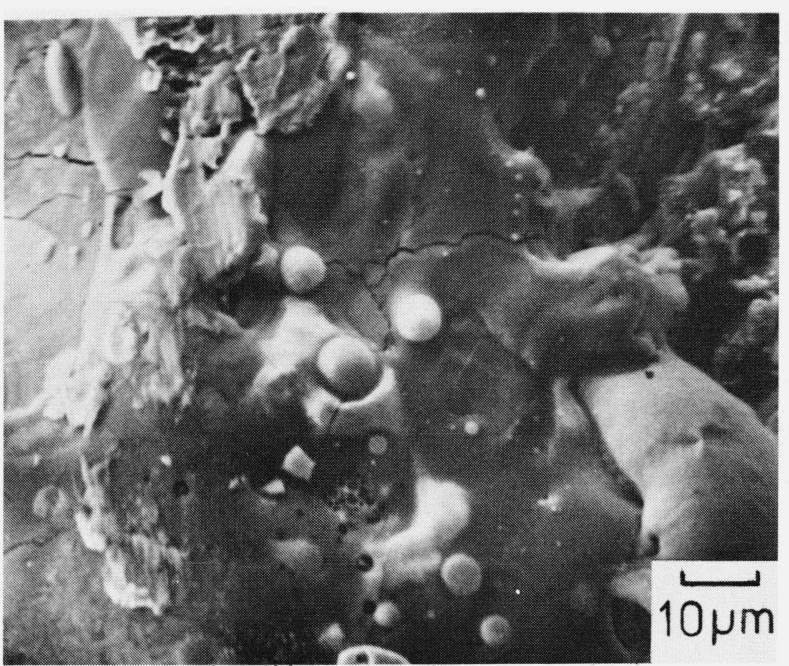

FIGURE 4(b). Ball-like structures observed in region of figure 4(a) (SEM image).

with only 2-4 percent aluminum [table 2, $\mathrm{Al}(2,7)$; $\mathrm{Fe}(4,5,8,9)]$. Elongated structures, indicated in figure 4(c), are also composed mainly of iron. The spherical and elongated structures appear to be the result of melting and rapid freezing of the metal. The presence of molten iron during the glow phenomena indicates that temperatures in excess of $1500{ }^{\circ} \mathrm{C}$ are generated in the region of the crater.

The imaging process in the scanning electron microscope is sensitive to the presence of insulating layers through the phenomenon of electrical charging. The presence of thick layers of aluminum oxide or iron oxide on the surface of the craters would be revealed in the scanning electron micrographs by bright regions characteristic of such 
TABLE 2. X-ray microanalysis of craters

\begin{tabular}{ccc}
\hline $\begin{array}{l}\text { Aluminum wire } \\
\text { location }\end{array}$ & $\begin{array}{c}\mathrm{Al} \\
(\mathrm{wt} \%)\end{array}$ & $\begin{array}{c}\mathrm{Fe} \\
(\mathrm{wt} \%)\end{array}$ \\
\hline 1 & 77 & 23 \\
2 & 4.8 & 95 \\
3 & 59 & 41 \\
4 & 73 & 27 \\
5 & 69 & 30 \\
6 & 96 & 3.9 \\
7 & 4.3 & 96 \\
8 & 15 & 85 \\
9 & 89 & 11.3 \\
10 & 12 & 88 \\
11 & 77 & 23
\end{tabular}

Iron Screw

\begin{tabular}{lcl}
\hline 1 & 16 & 84 \\
2 & 59 & 41 \\
3 & 73 & 26 \\
4 & 3.3 & 97 \\
5 & 2.2 & 97 \\
6 & 26 & 74 \\
7 & 58 & 41 \\
8 & 0.9 & 99 \\
9 & 1.6 & 99
\end{tabular}

Analysis of cross section

\begin{tabular}{cccc}
\hline Location & $\mathrm{Al}$ & $\mathrm{Fe}$ & $\mathrm{Cu}^{\prime}$ \\
\hline 1 & 10.1 & 88.0 & 1.5 \\
\hline
\end{tabular}

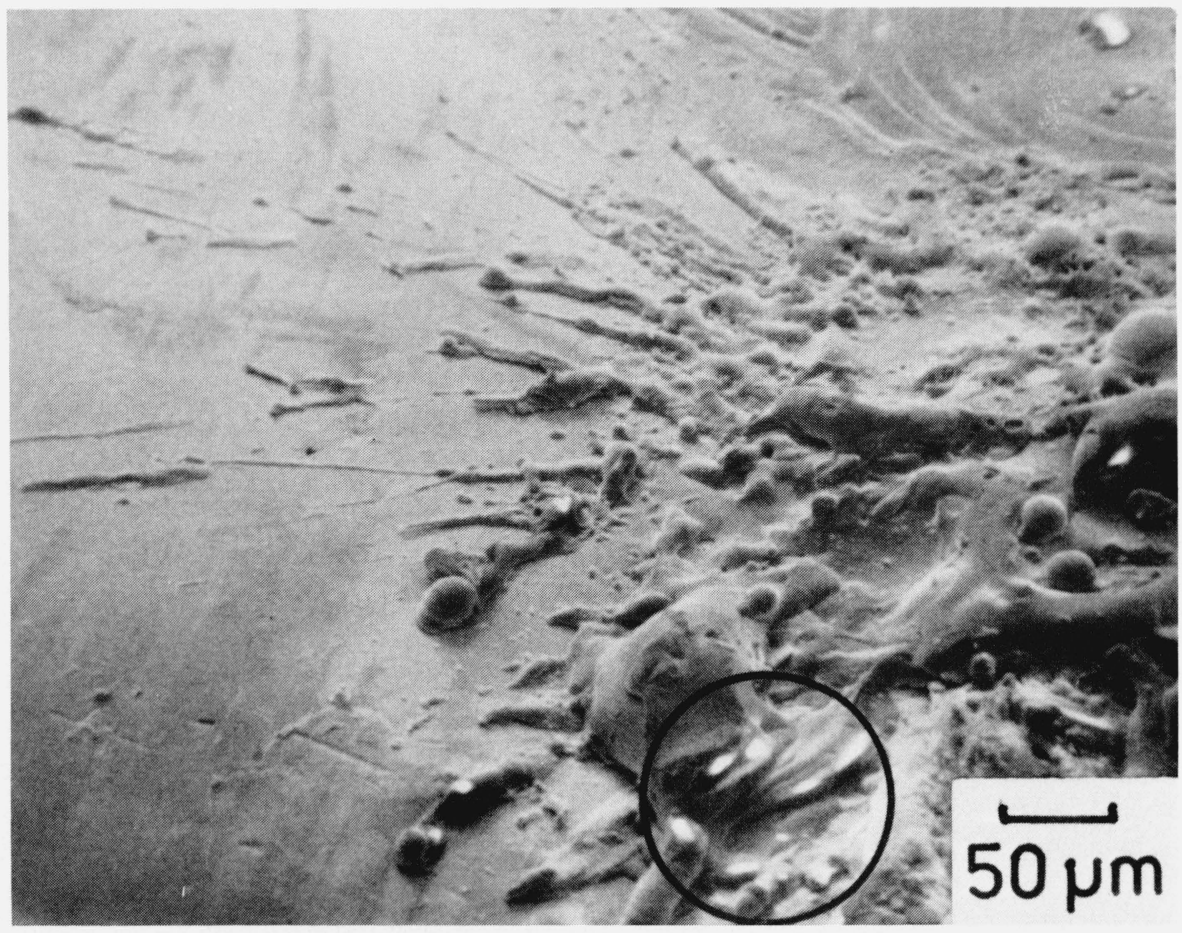

FIGURE 4(c). Splatter-like structures on edge of damage crater on iron screw. The circled area shows evidence of charging (bright areas) (SEM image). 


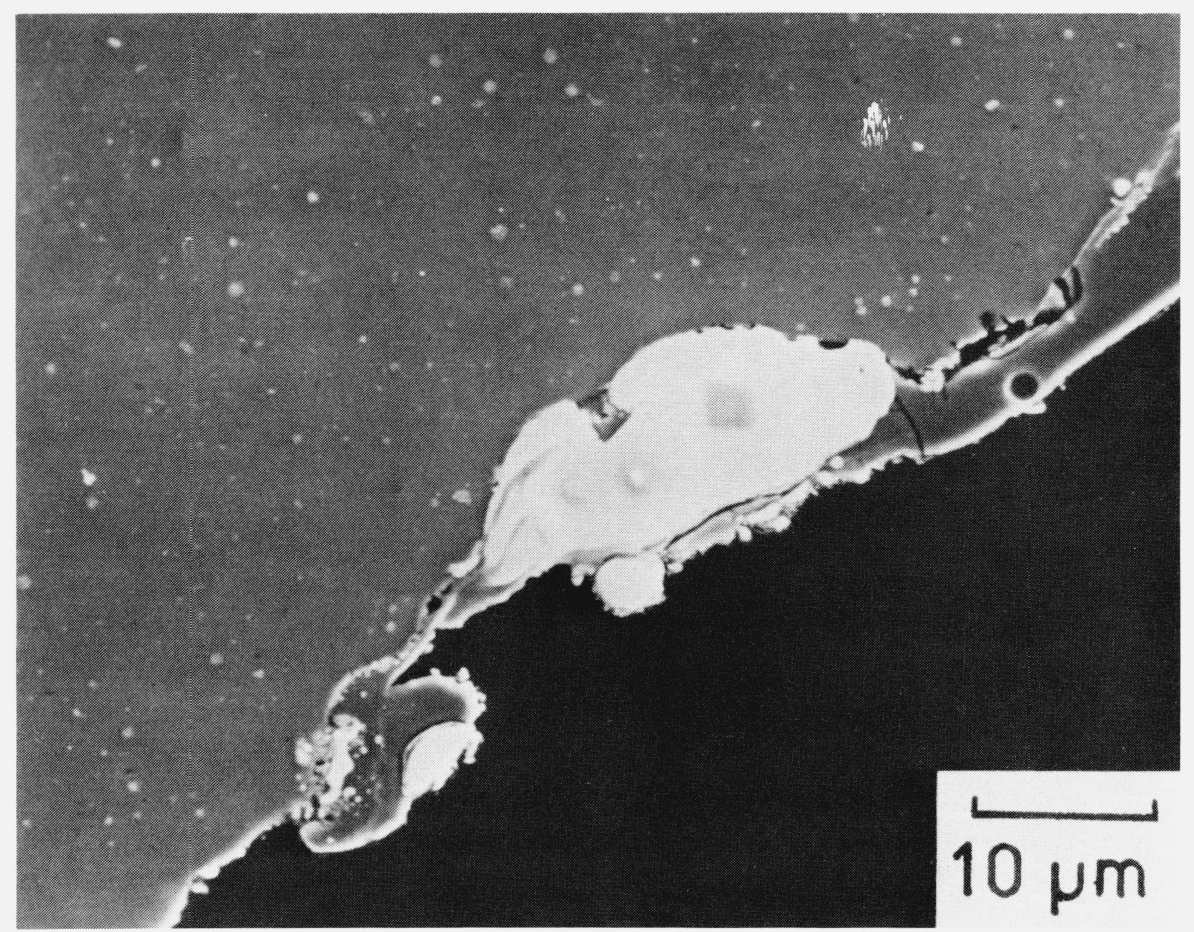

FIGURE 5. Metallographic cross section through a damage crater on aluminum wire (SEM image).

charging. These areas are occasionally observed within the craters, e.g., as indicated by circles in figures 3(a) and 4(c). The regions of charging in the image represent only a small portion of the crater area, and thus the dominant character of the crater is conductive.

\subsubsection{Interior}

The sub-surface structure of a crater formed during the glow process on the aluminum wire was examined in a metallographic cross section (fig. 5). The electron image of this structure reveals a new phase at the surface of the wire below the crater, which is found to contain principally aluminum and iron with a small amount of copper (table 2).

\subsection{Branch Circuit Receptacle Glow Failures}

\subsubsection{Long term sustained glow failures}

Sample A (table 1) underwent a sustained glow, $4 \mathrm{~h}$ in duration reaching a measured temperature of $350{ }^{\circ} \mathrm{C}$. The metallographic cross section (unetched, figs. 6(a) and 6(b)) showed evidence of extensive reaction at the aluminum wire/iron screw interface and at the aluminum wire/brass plate interface.

(a) Aluminum wire/iron screw interface. A backscattered electron image (which is sensitive to compositional differences) of the aluminum wire/iron screw interface, (fig. 7) reveals a complex reaction zone which consists of two distinct layers located between the aluminum and iron. Quantitative analyses (table 3A) performed at the locations indicated in figure 7 reveal that the thin outer layer (near the aluminum wire) consists of $62 \mathrm{wt} \% \mathrm{Al}-38 \mathrm{wt} \% \mathrm{Fe}-$ $0.5 \mathrm{wt} \% \mathrm{Cu}$ while the thick inner layer (near the iron screw) consists of $57 \mathrm{wt} \% \mathrm{Al}-43 \mathrm{wt} \% \mathrm{Fe}-0.1 \mathrm{wt} \% \mathrm{Cu}$. Zinc (from the brass electroplated coating) was not detected.

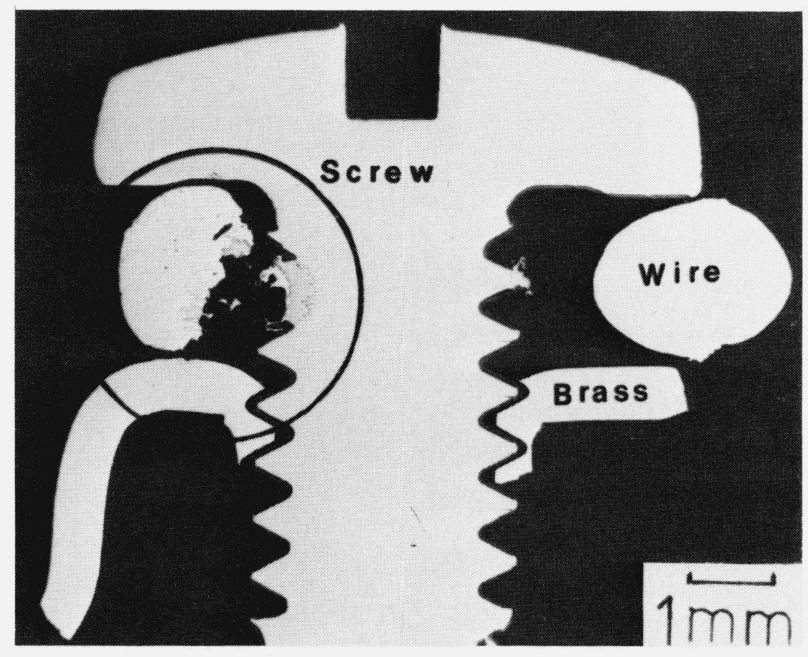

FIGURE 6(a). Optical micrograph of aluminum wire/iron screw/brass plate from duplex receptacle following glow failure (sample A, table 1). 


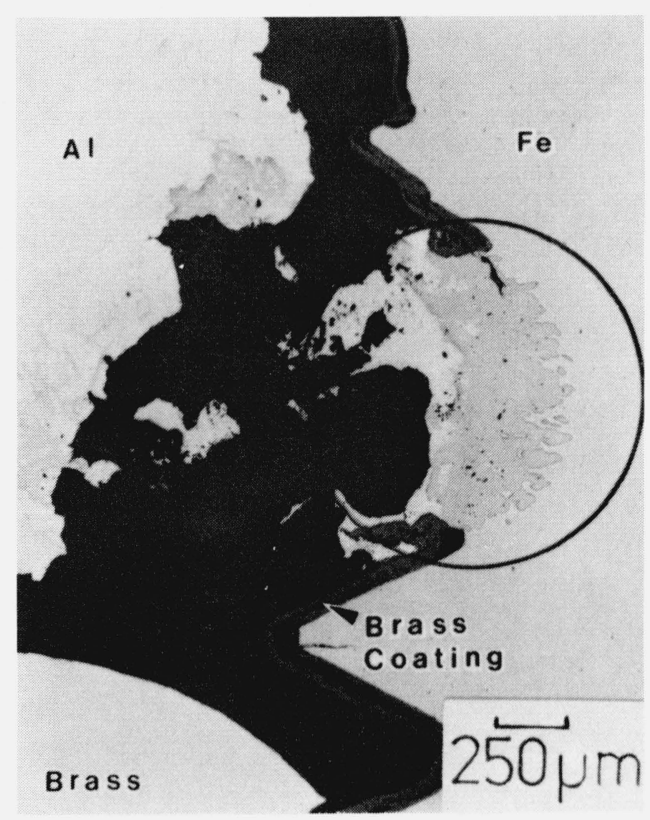

FIGURE 6(b). Optical micrograph of aluminum-iron region of figure 6(a) showing reaction zone (unetched).

TABLE 3A. X-ray microanalysis of section through duplex connector

\begin{tabular}{cccll}
\hline Location* & Al & Fe & Cu & Zn \\
\hline 1 & 62.5 & 38.1 & 0.5 & 0 \\
2 & 57.5 & 43.3 & 0 & 0 \\
3 & 57.3 & 43.3 & 0 & 0 \\
4 & 55.5 & 44.4 & 0 & 0 \\
\hline
\end{tabular}

* Locations marked in figure 7 .

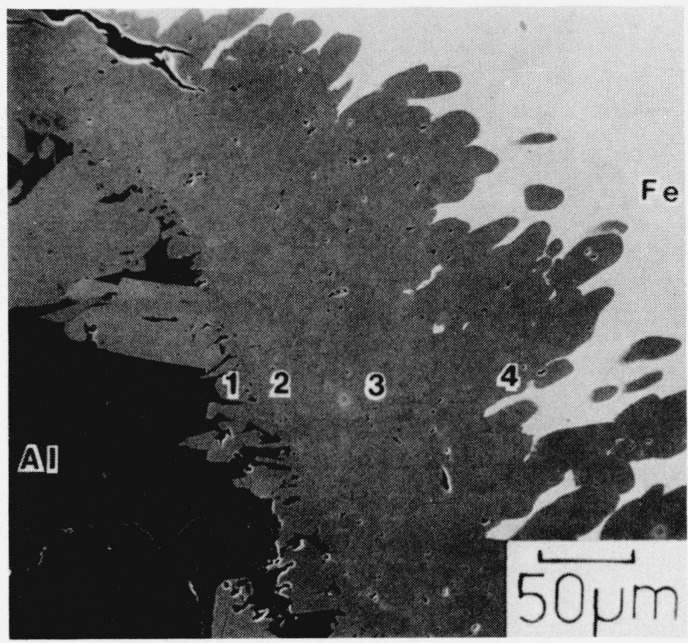

FigURE 7. SEM micrograph of the circled region of figure $6(b)$. The analyses at the indicated locations are listed in table $3 \mathrm{~A}$.
The interfaces of this reaction zone with the aluminum and with the iron are both highly irregular, which suggests that the zone is growing into both materials. In this sample, no evidence of a thick oxide layer was obtained.

The structures observed in sample A were typical for sustained glow failures. Oxide layers were not usually found. In one sample, however (sample B, table 1), a thick oxide layer was observed in addition to the usual aluminum-iron intermetallic layers. The optical micrograph (fig. 8) of the cross section of sample B shows the reaction zone ("Fe-Al") and the oxide layer. Selected points in these structures were analyzed, as shown in table $3 \mathrm{~B}$. The intermetallic layer (figs. 9(a) and 9(b)) contained two distinct regions, with the region adjacent to the wire slightly richer in aluminum. The oxide structure (fig. 9(c)) contained mainly aluminum (table $3 \mathrm{~B}$ ). Note that the measured aluminum weight fraction in this region; 71 percent, is substantially higher than aluminum in stoichiometric $\mathrm{Al}_{2} \mathrm{O}_{3}$ (weight percent $\mathrm{Al}$ is $53 \%$ ), which

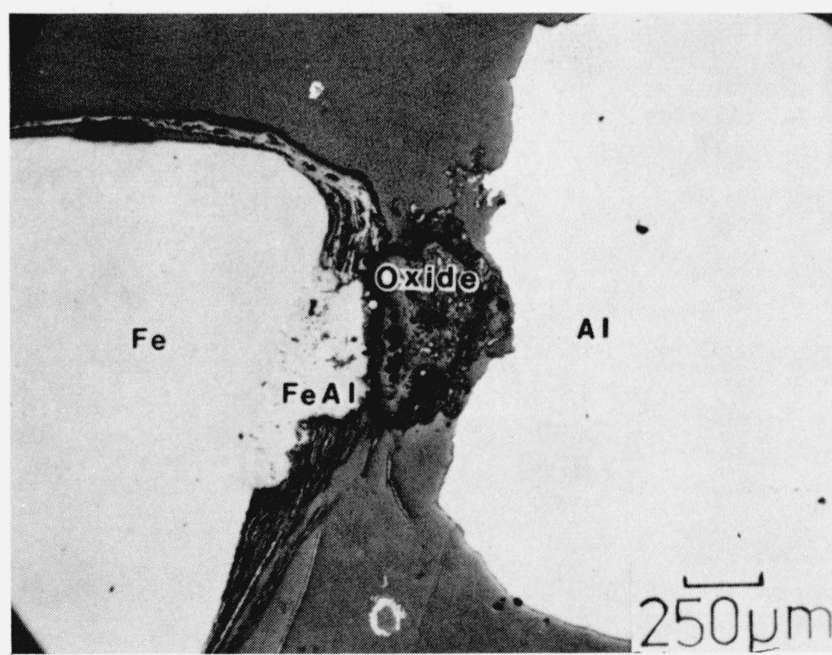

FIGURE 8. Optical micrograph of iron/aluminum interface region in sample $B$, table 1 , showing iron-aluminum interaction region and an oxidized region near the aluminum wire.

TABLE 3B. X-ray microanalysis of section through duplex connector

\begin{tabular}{llrll}
\hline Location* & Al & Fe & $\mathrm{Cu}$ & $\mathrm{Zn}$ \\
\hline 1 & 66.2 & 33.7 & 0.6 & 0 \\
2 & 61.3 & 39.0 & 0.2 & 0 \\
3 & 94.1 & 3.9 & 3.6 & 0.7 \\
4 & 66.3 & 35.0 & 0.4 & 0 \\
oxide & 71.1 & 0.4 & 0 & 0 \\
inclusion & & & \\
in oxide & 70.0 & 30.2 & 0 & 0 \\
All concentrations in weight percent. & & \\
\hline
\end{tabular}

${ }^{*}$ Locations marked in figure 9(a). 


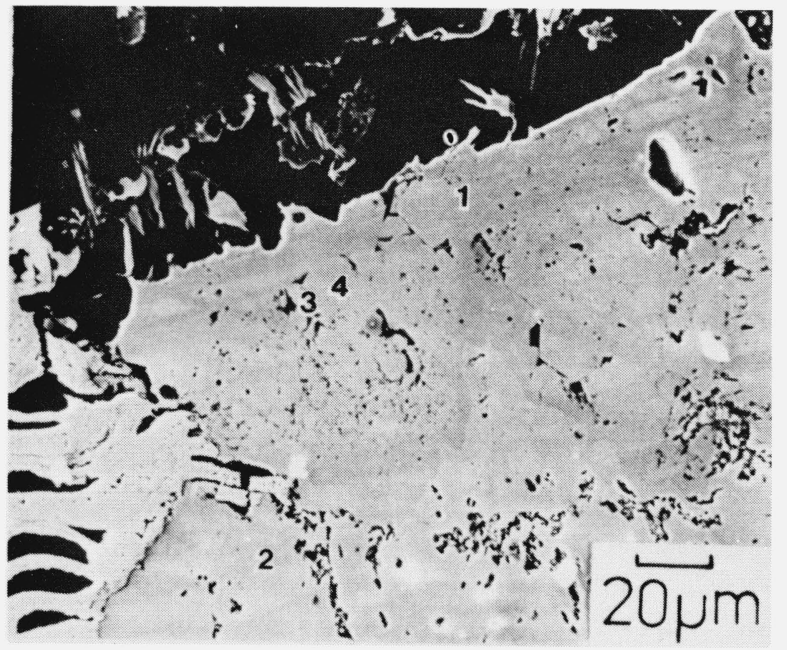

FIGURE 9(a). SEM image of iron/aluminum reaction region in figure 8.

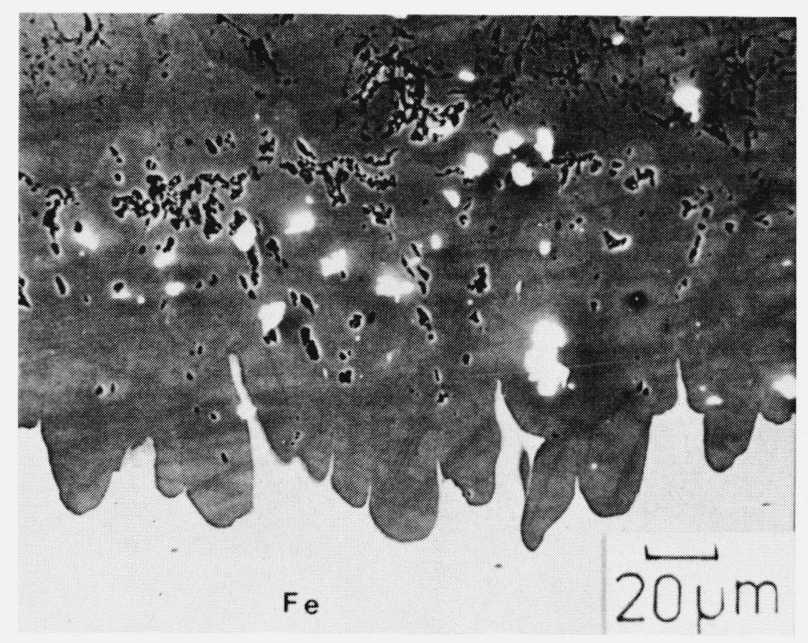

FIGURE 9(b). SEM image of interface between iron/aluminum reaction zone and iron screw in figure 8.

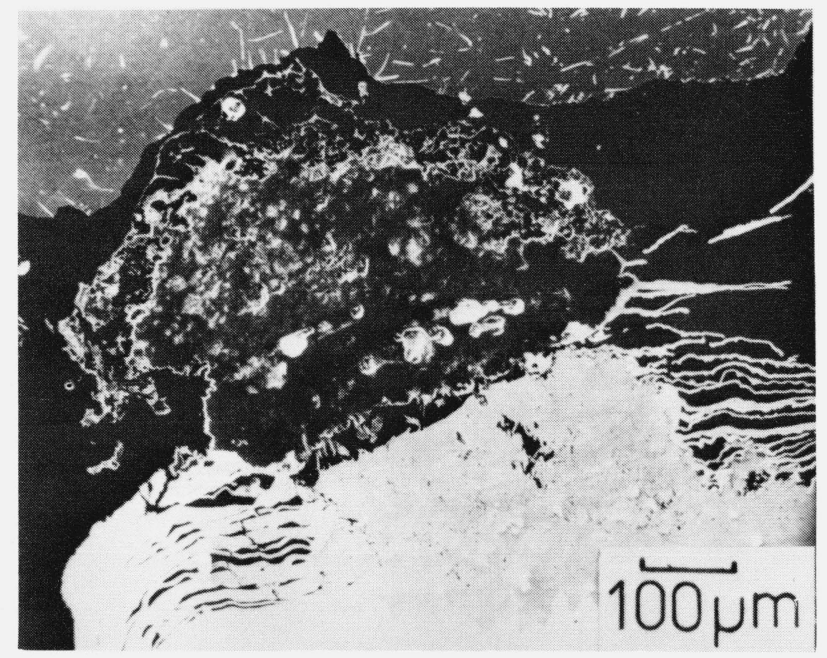

FIGURE 9(c). SEM image of oxide/iron-aluminum reaction zone in figure 8. indicates that the aluminum is incompletely oxidized. Inclusions are observed in this oxide layer which correspond to nonoxidized intermetallic compounds (table 3B).

(b) Brass-aluminum interface. Reactions are often observed as well at the interface between the aluminum wire and the brass plate. At the brass-aluminum interface in sample A (fig. 10) a structure is observed with a nearly radial symmetry. X-ray microanalysis at the points indicated in figure 11 reveals that this region is an
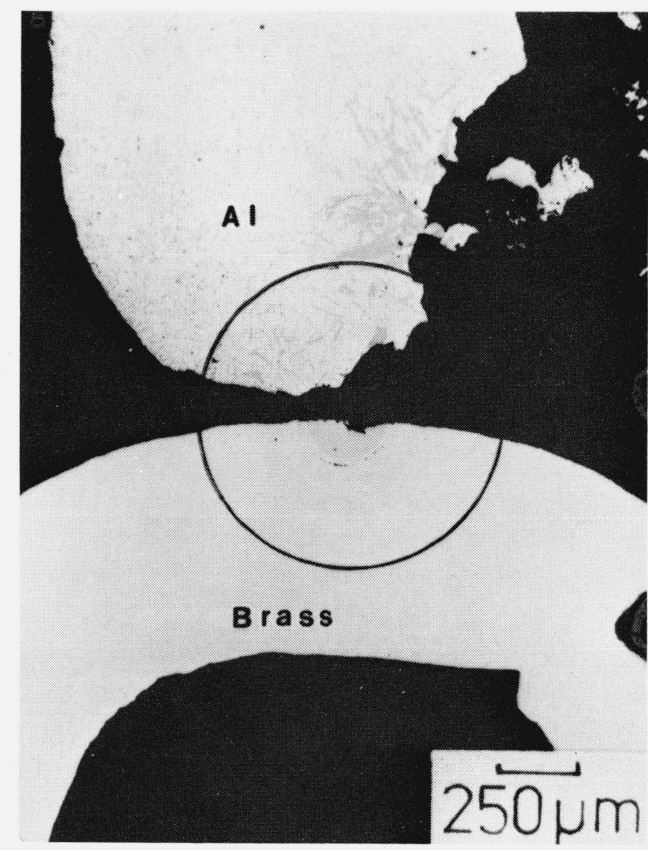

FIGURE 10. Optical micrograph of reaction zone at an aluminum wire/brass plate interface.

Reaction zone circled. Sample A, table 1 .

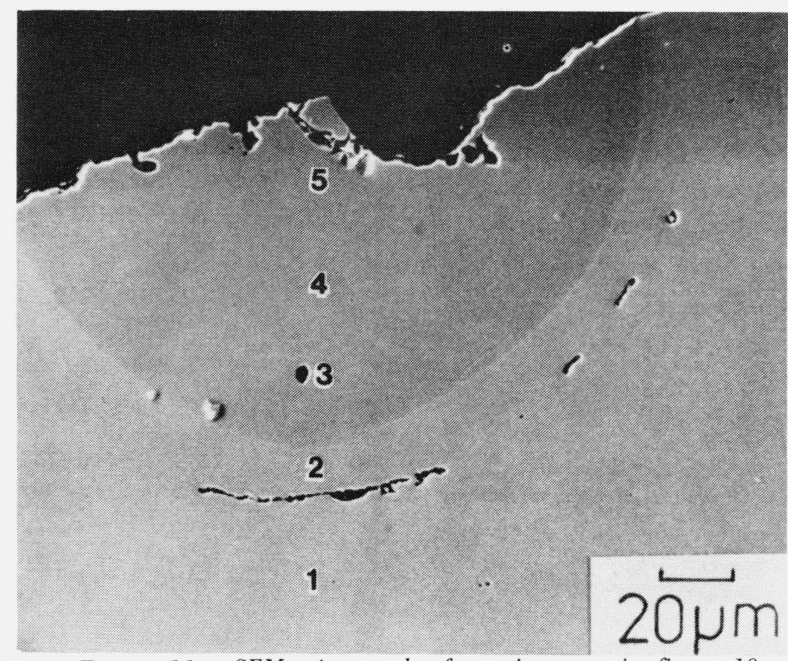

FIGURE 11. SEM micrograph of reaction zone in figure 10. Analyses at numbered locations are listed in table 4. 
aluminum-copper-zinc alloy which is slightly enriched in copper and strongly depleted in zinc as compared to the unaffected region of the brass plate (table 4).

TABLE 4. X-ray microanalysis of section through duplex connector

\begin{tabular}{clllr}
\hline Point* & Al & Fe & Cu & Zn \\
\hline 1 & 5.2 & 0 & 65.0 & 29.7 \\
2 & 16.4 & 0.9 & 72.4 & 10.2 \\
3 & 18.4 & 0 & 74.2 & 7.3 \\
4 & 18.7 & 0 & 74.6 & 6.8 \\
5 & 19.1 & 0 & 74.3 & 6.5 \\
bulk brass & 0 & 0 & 69.4 & 31.1
\end{tabular}

All concentrations in weight percent.

* Locations marked in figure 11.

\subsubsection{Incipient glow failures}

A series of circuit connections was tested to examine the initial stages of the failure mechanism by interrupting the test after a small number of cycles prior to the development of a visible glow. Structures relating to incipient failure were found at both the aluminum wire/iron screw interface and the aluminum wire/brass plate interface. Because of the small size of the regions of incipient failure, locating the regions of interest in the metallographic cross section was difficult. Ten receptacles were sectioned to yield the following observations.

(a) Aluminum wire/iron screw interface. An example of a structure formed at the wire/screw interface during the early stages of a glow failure (sample C, table 1 ) is illustrated in figure 12. The structure consists of two distinct aluminum-iron regions with the compositions listed in table 5 . The reaction region in figure 12 has only a small

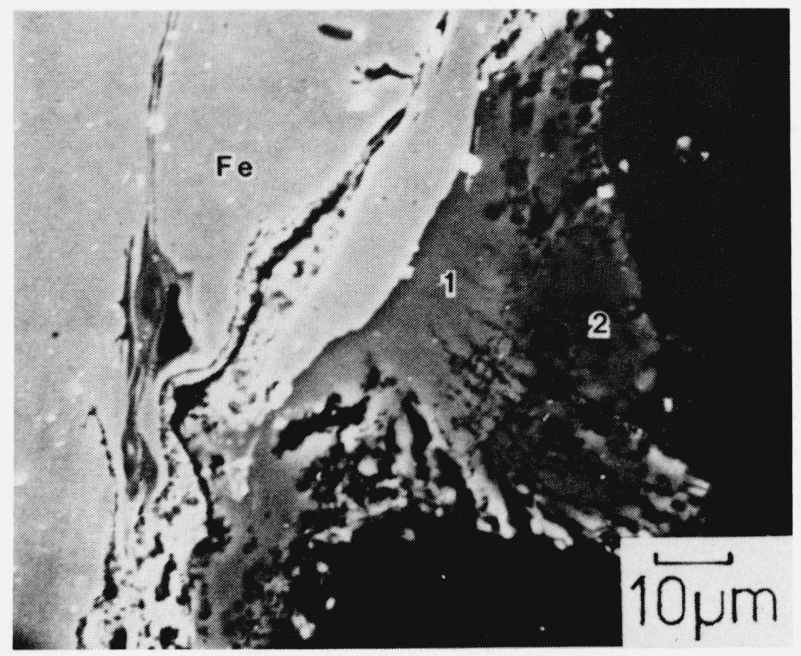

FIGURE 12. Incipient reaction zone at iron/aluminum interface. Analyses at numbered locations are listed in table 5 . percentage of the volume of the reaction zone developed in a sample such as $\mathrm{A}$ in which a sustained glow occured. A major difference between the reaction zone formed in the initial stage and the fully-developed reaction zone is the detection of a large amount of zinc, which is derived from a galvanized zinc coating. In fully-developed reaction zones associated with galvanized screws, the zinc component is apparently lost by volatization.

(b) Aluminum wire/brass plate interface. Two different types of structures are observed at the brass-aluminum interface. In one type of structure a complex layered reaction zone is found at the aluminum wire/brass plate interface during the initial stages of the failure (sample 1). A scanning electron micrograph (fig. 13) reveals that this region contains at least four distinct zones. The analyses of these areas (table 5) indicate that the formation of an aluminum-copper-zinc alloy has occurred during the failure.

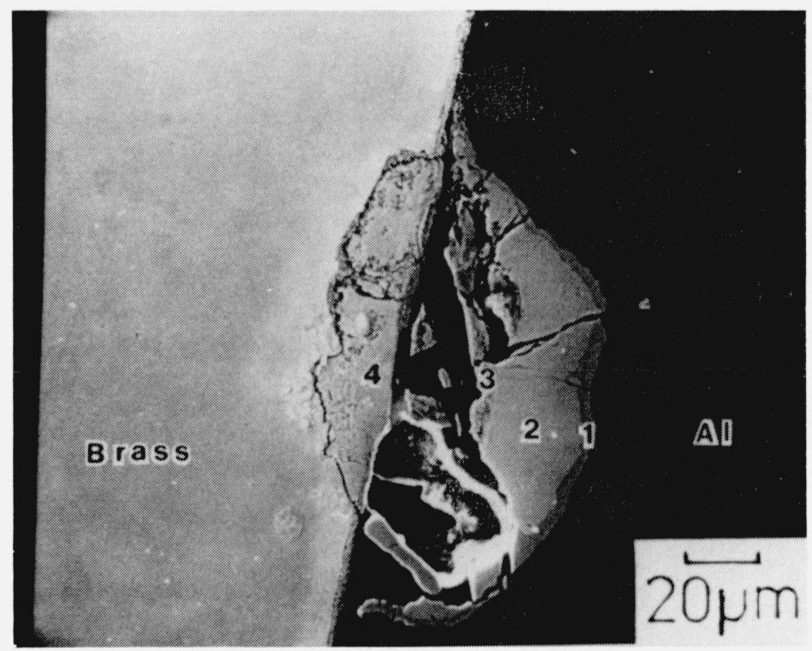

FIGURE 13. Incipient reaction zone at aluminum/brass interface.

The aluminum content of the alloy increases near the wire. A second type of structure can be observed at the aluminum-brass interface (fig. 14(a)) which consists of a mixture of two distinct phases (table 5, sample C). The continuous phase "C" (fig. 14(b)) consists principally of. aluminum and copper with a minor amount of zinc. In the discontinuous phase "D", aluminum and zinc are present as major constituents, while copper is a minor constituent.

\section{Discussion}

The observations of the structure and composition of the regions on the aluminum wire, steel screw, and brass plate components affected by the glow failure mechanism can be summarized as follows: (1) High temperatures are created in the region of the glow discharge. The observation of 


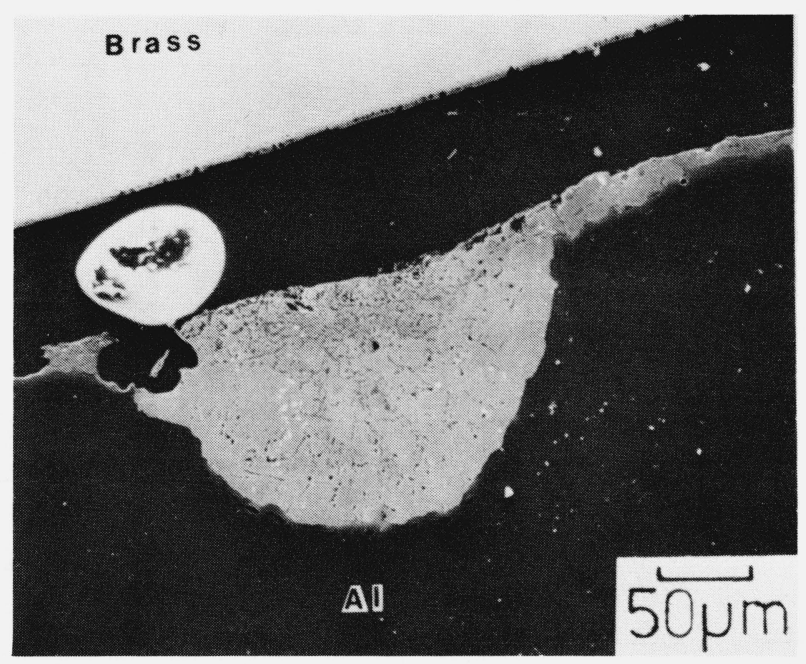

FIGURE 14(a). Incipient reaction zone at aluminum/brass interface.

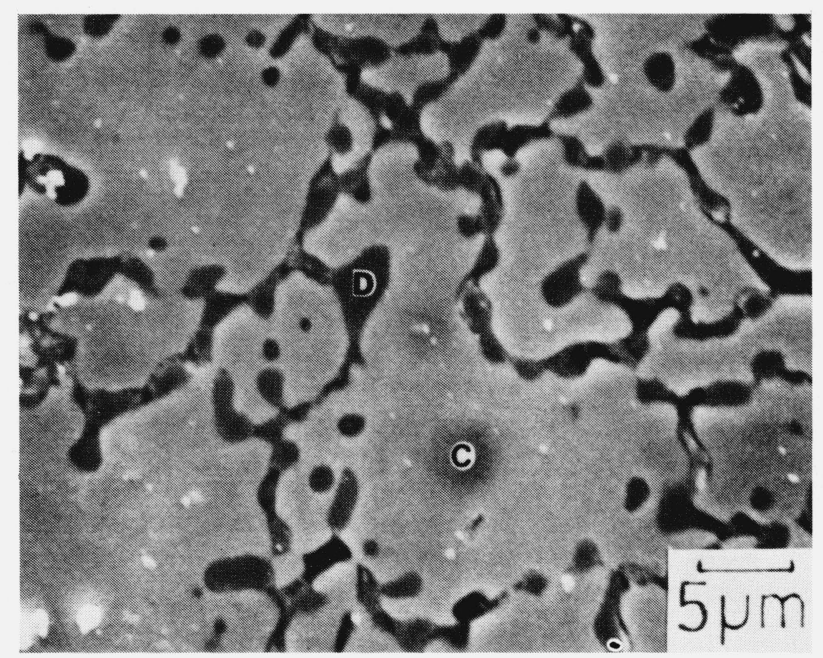

FIGURE 14(b). Higher magnification image of figure 14(a) showing continuous ("C") phase and discontinuous phase ("D").

structures of solidified iron suggests the development of temperatures in excess of $1500^{\circ} \mathrm{C}$. (2) Material transport occurs between the members of the wire/screw couple and the wire/brass plate couple, initially in the vapor phase and possibly in the liquid phase after sustained glow. (3) Reaction of these metals occurs creating thick zones of alloy products which intrude into the wire, screw, and plate. In the case of the aluminum-iron reaction, initially a single phase is formed. Further reaction results in the formation of multiple layers of distinctly different composition. Each layer appears to be single phase. At the brass-aluminum interface, a two-phase structure or a layered structure of single phase layers can form.
TABLE 5. Analysis of structures associated with incipient glow failure

Aluminum Wire/Iron Screw Interface

\begin{tabular}{ccccc}
\hline Location* $^{*}$ & $\mathrm{Al}$ & $\mathrm{Fe}$ & $\mathrm{Cu}$ & $\mathrm{Zn}$ \\
\hline 1 & 50.3 & 37.8 & 0 & 12.8 \\
2 & 62.3 & 33.1 & 0 & 4.4 \\
\hline
\end{tabular}

* Locations marked in figure 12.

Aluminum Wire/Brass Plate Interface

(a) Layered structure

\begin{tabular}{ccccc}
\hline Location* & $\mathrm{Al}$ & $\mathrm{Fe}$ & $\mathrm{Cu}$ & $\mathrm{Zn}$ \\
\hline & & & & \\
1 & 50.2 & 0 & 48.3 & 3.1 \\
2 & 26.0 & 0 & 56.3 & 19.1 \\
3 & 32.3 & 0 & 47.9 & 18.9 \\
4 & 20.3 & 0 & 52.7 & 24.9 \\
\hline
\end{tabular}

* Locations marked in figure 13.

Aluminum Wire/Brass Plate Interface

(b) Two-phase structure

\begin{tabular}{lccrr}
\hline \multicolumn{1}{c}{ Location* } & $\mathrm{Al}$ & $\mathrm{Fe}$ & $\mathrm{Cu}$ & $\mathrm{Zn}$ \\
\hline Continuous phase & 49.6 & 0 & 49.3 & 2.5 \\
Discontinuous phase & 67.2 & 0 & 7.9 & 26.0 \\
\hline
\end{tabular}

${ }^{*}$ Locations marked in figure 14(b).

The binary phase diagrams of $\mathrm{Al}-\mathrm{Fe}$ and $\mathrm{Al}-\mathrm{Cu}$ contain numerous intermetallic compounds (table 6 [8]). Comparison of the analytical results on the structures observed in the cross-sections of high resistance aluminum/iron and aluminum/brass junctions reveals that, in many cases, the structures formed are intermetallic compounds.

In the iron-aluminum junctions, the initial phase observed in the reaction zone (table 2) corresponds closely in composition to $\mathrm{Fe}_{3} \mathrm{Al}$. In the samples in which the reaction proceeded to a greater extent (table $3 \mathrm{~A}$ ) the layers in the structure correspond approximately to $\mathrm{Fe}_{2} \mathrm{Al}_{5}$ and $\mathrm{FeAl}_{3}$. Note that the intermetallic compounds generally have a range of composition over which they are stable and thus the observed values may not correspond exactly to the stoichiometric values.

In the case of the aluminum-brass reactions, the situation is more complex. For sample A (table 4), the single phase reaction product [approximately $\mathrm{Cu}(74)-\mathrm{Zn}(7)-\mathrm{Al}(18)$ ] appears to be $\mathrm{Cu}_{9} \mathrm{Al}_{4}$ with some replacement of copper by zinc. For the layered structure observed in sample $\mathrm{C}$ [table 5(b)], layer 1 is $\mathrm{CuAl}_{2}$, while layers 2,3 , and 4 are probably a variety of intermetallics $\left(\mathrm{Cu}_{4} \mathrm{Al}_{3}, \mathrm{CuAl}\right.$, and $\mathrm{Cu}_{3} \mathrm{Al}_{2}$ ) with zinc partially replacing copper. In the two 
phase structure observed in sample D [table 5(c)], the continuous phase is $\mathrm{CuAl}_{2}$ (with a small amount of zinc) and the discontinuous phase is an aluminum solid solution.

The observation of the formation of intermetallic phases at the current-carrying interface in aluminum/iron and aluminum/brass connections is critical to understanding the development of high resistance junctions in these connections. The resistivity of solid solution alloys is, in general, higher than the resistivity of pure metals due to disruption of the matrix lattice by substitutional or interstitial solute atoms. In the case of intermetallic compounds, such as those listed in table 6 , the resistivity can be a factor of 10 or more higher than that of the pure metals, because of the localization of electrons in chemical bonds. In the Al-Fe system, the resistivity of the intermetallic phases is as much as a factor of 50 greater than the resistivity of pure aluminum and 10 times greater than the resistivity of pure iron, figure 15 [10]. The maximum resistivity in this system is of the order of 100-200 $\mu \Omega$ $\mathrm{cm}$, which is similar to the resistivity of the alloy nichrome. To obtain the resistance of an intermetallic deposit with the complex topographic structure shown in figures 6(a), (b) and 7 would require a detailed study of the morphology and interconnections of the three dimensional object.

TABL.E 6. Intermetallic compounds [8,9]

\begin{tabular}{lccc}
\hline Fe-Al system & $\mathrm{Al}$ & $\mathrm{Fe}$ & $\begin{array}{c}\text { Approximate } \mathrm{Al} \\
\text { range of } \\
\text { stability }\end{array}$ \\
\hline $\mathrm{Fe}_{3} \mathrm{Al}$ & 13.9 & 86.1 & $12-18$ \\
$\mathrm{FeAl}$ & 32.6 & 67.4 & $\begin{array}{c}\text { stoichiometric } \\
\text { stoichiometric }\end{array}$ \\
$\mathrm{FeAl}_{2}$ & 49.1 & 50.9 & $53-57$ \\
$\mathrm{Fe}_{2} \mathrm{Al}_{5}$ & 54.7 & 45.3 & $58-63$ \\
$\mathrm{FeAl}_{3}$ & 59.2 & 40.8 & $\begin{array}{c}\text { Approximate } \mathrm{Al} \\
\text { range of } \\
\text { stability }\end{array}$ \\
& & & $44-46$ \\
$\mathrm{Cu}-\mathrm{Al} \mathrm{system}$ & $\mathrm{Al}$ & $\mathrm{Cu}$ & $29-31$ \\
\hline $\mathrm{CuAl}_{2}$ & 45.9 & 54.1 & $24-26$ \\
$\mathrm{CuAl}_{\mathrm{Cu}} \mathrm{Al}_{3}$ & 29.8 & 70.2 & $21-23$ \\
$\mathrm{Cu}_{3} \mathrm{Al}_{2}$ & 24.2 & 75.8 & $16-20$ \\
$\mathrm{Cu}_{9} \mathrm{Al}_{4}$ & 22.1 & 77.9 & \\
\hline
\end{tabular}

Zn-Al system

— no intermetallics

\begin{tabular}{cccc}
\hline $\mathrm{Cu}-\mathrm{Zn}-\mathrm{Al}$ system & $\mathrm{Cu}$ & $\mathrm{Zn}$ & $\mathrm{Al}$ \\
\hline $\mathrm{Cu}_{2} \mathrm{ZnAl}$ & 55 & 32 & 13 \\
$\mathrm{Cu}_{3} \mathrm{ZnAl}_{6}$ & 56 & 12 & 32 \\
\hline
\end{tabular}

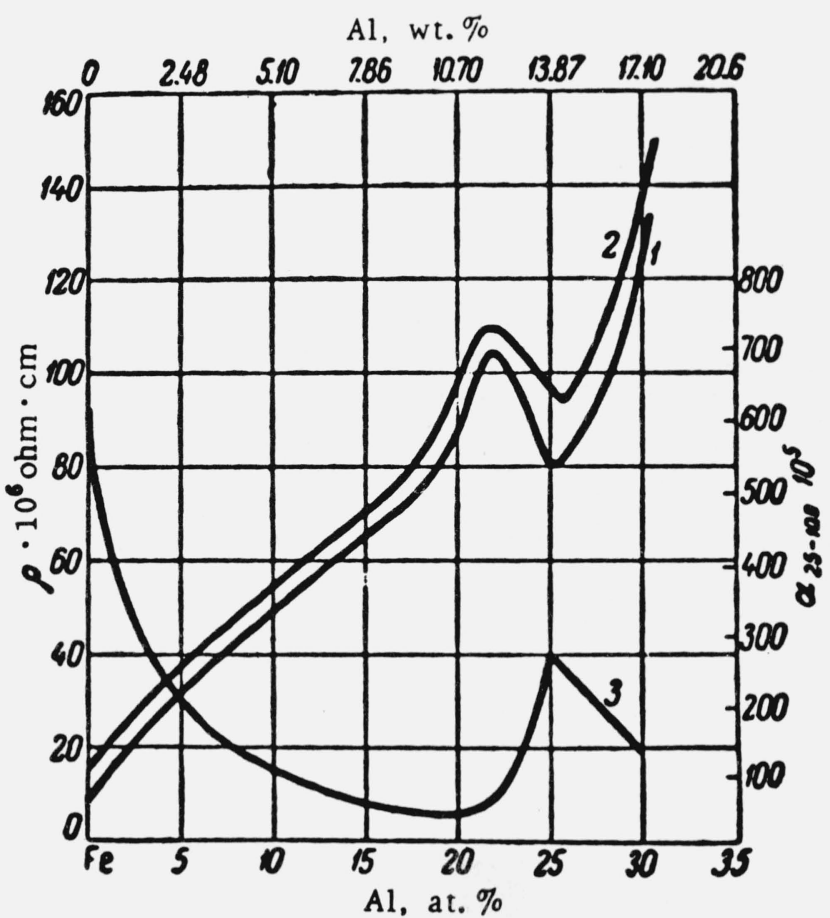

FiguRE 15. Resistivity behavior in the iron-aluminum phase diagram (ref. 8).

Calculations indicate that the resistance of the individual "fingerlike" protuberances observed at the interface is of the order of $0.5 \Omega$ for a structure with dimensions of 250 $\mu \mathrm{m}$ length, a cross sectional area of $625 \mu \mathrm{m}^{2}$ and a resistivity of $100 \mu \Omega-\mathrm{cm}$. From the morphology of the interface, many of these structures may operate in parallel, although the exact number of active sites is difficult to determine because of voids. The estimate of the junction resistance in glowing circuits is of the order of $0.1 \Omega$ [1]. The values suggested by the resistance of an individual finger does not seem inconsistent with these measurements. The formation of intermetallic compounds at the currentcarrying interfaces in aluminum wire/iron screw and aluminum wire/brass plate connections may thus be an important factor in the mechanism of high resistance junction formation.

The formation of intermetallic compounds as a mechanism for high resistance junctions is more reasonable than postulating that aluminum oxide is the prime factor. Although there is some evidence for aluminum oxide at the surface of the arc-damage craters, the resistivity of aluminum oxide is so great that extensive formation of aluminum oxide at the current carrying interface would reduce the current flow to a negligible level. Intermetallic compounds, on the other hand, have sufficient conductivity to allow the current to continue to flow, while providing a significant increase in resistance so that the $I^{2} R$ heating losses can become large. 


\section{Conclusions}

(1) The glow-arc process which occurs in mechanically loose aluminum wire/iron screw and aluminum wire/brass plate connections results in locally high temperatures and causes material transport between the members of the connections.

(2) Under these conditions of high temperatures and intimate mixing the elements react to form intermetallic compounds, such as $\mathrm{FeAl}_{3}$ and $\mathrm{CuAl}_{2}$, and solid solutions.

(3) The resistivity of these intermetallic compounds may be one of the main factors causing high resistance junction formation in these connections.

The outstanding work of Mr. Charles Brady, who prepared the metallographic sections used in this work, is gratefully acknowledged by the authors.

\section{References}

[1] Meese, W. J. and Beausoliel, R. W., Exploratory study of glowing electrical connections, Nat. Bur. Stand. (U.S.), Bldg. Sci. Ser. 103 (Oct. 1977).
[2] Rabinow, J., Some thoughts on electrical connections, Nat. Bur. Stand. (U.S.) NBSIR 78-1507 (Aug. 1978).

[3] Rabinow, J., Special report on aluminum wire, Report for the U.S. Consumer Product Safety Commission (Sept. 1974).

[4] Suzuki, H., Inoue, S., Tago, M., and Umemura, T., $\mathrm{Cu}_{2} \mathrm{O}$ breeding phenomena in electrical connections, Report to the Furukawa Electric Co., Ltd., Japan.

[5] Myklebust, R. L., Fiori, C. E., and Heinrich, K. F. J., FRAME C: A compact procedure for quantitative energy-dispersive electron probe x-ray analysis, Nat. Bur. Stand. (U.S.), Tech. Note 1106 (Sept. 1979).

[6] Small, J. A., Heinrich, K. F. J., Newbury, D. E., and Myklebust, R. L., Progress in the development of the peak-to-background method for the quantitative analysis of single particles with the electron probe, SEM/1979 (SEM, Inc., Chicago, 1979), Vol. 2, 807-816.

[7] Small, J. A., Newbury, D. E., and Myklebust, R. L., Analysis of particles and rough samples by FRAME P, a ZAF method incorporating peak-to-background measurements, Microbeam Analysis-1979, D. E. Newbury, ed., (San Francisco Press, 1979) 243-246.

[8] Hansen, M., Constitution of Binary Alloys (McGraw-Hill, New York, 1958) 84-95.

[9] Metals Handbook, Vol. 8., Metallography, Structure and Phase Diagrams, (American Society for Metals, Metals Park, OH, 1973) 391-392.

[10] Vol, A. E., Handbook of Binary Metallic Systems (translated from Russian), (Dept. of Commerce (U.S.), Washington, DC, 1966) p. 146 (fig. 61). 